\title{
Effects of internal mixing and aggregate morphology on optical properties of black carbon using a discrete dipole approximation model
}

\author{
B. V. Scarnato ${ }^{1, *}$, S. Vahidinia ${ }^{1,2}$, D. T. Richard ${ }^{3}$, and T. W. Kirchstetter ${ }^{4,5}$ \\ ${ }^{1}$ Bay Area Environmental Research Institute, NASA Ames Research Center, Moffett Field, CA 94035, USA \\ ${ }^{2}$ Oak Ridge Associated Universities, NASA Ames Research Center, MS 245-5, Moffett Field, CA 94035-1000, USA \\ ${ }^{3}$ Lawrence Livermore National Laboratory, 7000 East Ave, Livermore, CA 94550, USA \\ ${ }^{4}$ Environmental Energy Technologies Division, Lawrence Berkeley National Laboratory, Berkeley, CA 94720, USA \\ ${ }^{5}$ Department of Civil and Environmental Engineering, University of California, Berkeley, CA 94720-1710, USA \\ * currently at: Dept. of Meteorology, Naval Postgraduate School, Monterey, CA 93943, USA \\ Correspondence to: B. V. Scarnato (barbara.v.scarnato@ nasa.gov)
}

Received: 3 August 2012 - Published in Atmos. Chem. Phys. Discuss.: 5 October 2012

Revised: 18 February 2013 - Accepted: 4 March 2013 - Published: 16 May 2013

\begin{abstract}
According to recent studies, internal mixing of black carbon (BC) with other aerosol materials in the atmosphere alters its aggregate shape, absorption of solar radiation, and radiative forcing. These mixing state effects are not yet fully understood. In this study, we characterize the morphology and mixing state of bare $\mathrm{BC}$ and $\mathrm{BC}$ internally mixed with sodium chloride $(\mathrm{NaCl})$ using electron microscopy and examine the sensitivity of optical properties to BC mixing state and aggregate morphology using a discrete dipole approximation model (DDSCAT). DDSCAT is flexible in simulating the geometry and refractive index of particle aggregates. DDSCAT predicts a higher mass absorption coefficient (MAC), lower single scattering albedo (SSA), and higher absorption Angstrom exponent (AAE) for bare BC aggregates that are lacy rather than compact. Predicted values of SSA at $550 \mathrm{~nm}$ range between 0.16 and 0.27 for lacy and compact aggregates, respectively, in agreement with reported experimental values of $0.25 \pm 0.05$. The variation in absorption with wavelength does not adhere precisely to a power law relationship over the 200 to $1000 \mathrm{~nm}$ range. Consequently, AAE values depend on the wavelength region over which they are computed. The MAC of BC (averaged over the $200-1000 \mathrm{~nm}$ range) is amplified when internally mixed with $\mathrm{NaCl}$ (100-300 $\mathrm{nm}$ in radius) by factors ranging from 1.0 for lacy $\mathrm{BC}$ aggregates partially immersed in $\mathrm{NaCl}$ to 2.2 for compact $\mathrm{BC}$ aggregates fully immersed in $\mathrm{NaCl}$.
\end{abstract}

The SSA of BC internally mixed with $\mathrm{NaCl}$ is higher than for bare $\mathrm{BC}$ and increases with the embedding in the $\mathrm{NaCl}$. Internally mixed BC SSA values decrease in the $200-400 \mathrm{~nm}$ wavelength range, a feature also common to the optical properties of dust and organics. Linear polarization features are also predicted in DDSCAT and are dependent on particle size and morphology.

This study shows that DDSCAT predicts complex morphology and mixing state dependent aerosol optical properties that have been reported previously and are relevant to radiative transfer, climate modeling, and interpretation of remote sensing measurements.

\section{Introduction}

The most recent Intergovernmental Panel on Climate Change report (IPCC, 2007) established that the radiative forcing of all aerosol types should be estimated in order to understand their effects on the earth-atmosphere energy budget. The successful accomplishment of this goal requires an accurate parameterization of aerosol optical properties consistent with their physical and chemical properties. This study focuses on black carbon (BC), a product of combustion of fossil and biomass fuels, which is the strongest sunlight-absorbing aerosol species (Jacobson, 2001) and a critical component of 
the global and regional climate (Bond et al., 2004; Bond and Mikhailov, 2005; Ramanathan and Carmichael, 2008).

When aerosols are transported far from their emission sources, their climatic and environmental impacts are delocalized from their source regions (Kanakidou et al., 2005; Pace et al., 2006; Smirnov et al., 2011). During atmospheric transport, $\mathrm{BC}$ becomes increasingly mixed with weak or nonabsorbing materials, such as sulfates, nitrates, organics, dust, and sea salt (Li et al., 2003; Mikhailov et al., 2006; Shiraiwa et al., 2007, 2010; Xue et al., 2009; Moffet and Prather, 2009; Bueno et al., 2011; Laskin et al., 2012). The absorbing and scattering efficiencies of $\mathrm{BC}$ particles, which are aggregates of primary spherules, i.e., monomers (Tian et al., 2006), depend on primary spherule size, aggregate compactness, and mixing state with other species. Aggregate compactness (fractal dimension) is affected by temperature changes, water, and other aerosol material.

For example, laboratory experiments show that $\mathrm{BC}$ aggregates become more compact when embedded in lowviscosity materials, such as glutaric and sulfuric acids (Xue et al., 2009; Zhang et al., 2008). Also, coating BC with non-absorbing compounds, including organic and inorganic acids, leads to an enhancement in light absorption and scattering (e.g., Zhang et al., 2008; Xue et al., 2009; Shiraiwa et al., 2010). Xue et al. (2009) found that (i) thin coatings of dicarboxylic acids on BC aggregates enhance light scattering significantly and light absorption slightly and (ii) humidity cycling of glutaric acid coated BC can irreversibly restructure $\mathrm{BC}$ aggregates and further modify SSA.

These studies indicate that it is necessary to account for the optical effects of changes to the mixing state and morphology of $\mathrm{BC}$ particles when modeling their interaction with sunlight. However, optical properties are not always reproduced by commonly used models, such as the Lorenz-Mie-Debye theory (Bohren and Huffman, 1983), the Rayleigh-DebyeGans (RDG) approximation (Zhao and Ma, 2009) and the effective medium theory (Bruggeman, 1935; Maxwell Garnett, 1904). For example, there is a discrepancy between modeled and measured mass absorption coefficient (MAC) of bare BC aggregates (Bond and Bergstrom, 2006; Kahnert, 2010a,b). Bueno et al. (2011) found that the amplification in absorption observed when $\mathrm{BC}$ was coated with a surrogate of sulfuric acid was smaller than the predictions using core-shell Mie theory, and they suggested that the discrepancy was due to misrepresentation of the morphology of the coated particles and/or structure of the BC core in the model.

The optics of particles with complex shapes and refractive index distribution can only be calculated using computationally intensive techniques such as T-matrix and discrete dipole approximation (DDA). T-matrix is applicable to homogeneous particles (Mishchenko et al., 1996), while DDA is applicable to both homogeneous particles and particles with anisotropic composition (Purcell and Pennypacker, 1973; Draine and Flatau, 1994, 2010).
Recent studies show the optical effects of (i) treating bare $\mathrm{BC}$ as an aggregation of spherical primary particles rather than as a single sphere (e.g., Liu et al., 2008; Kahnert, 2010a,b; Kahnert and Devasthale, 2011; Wu et al., 2012) and (ii) $\mathrm{BC}$ aggregates embedded in other materials (e.g., Liu et al., 2012; Kahnert et al., 2012; Adachi et al., 2010; Liou et al., 2011; Worringen et al., 2008). The studies on bare $\mathrm{BC}$ make use of T-matrix, while those on coated BC aggregates make use of core-mantle theory involving two effective medium theories (Liu et al., 2012); finite difference time domain (Wu et al., 2012) in the IR region and DDA (Adachi et al., 2010; Kahnert et al., 2012). Liu et al. (2008) showed that the relationship between the absorption cross section and the compactness of the $\mathrm{BC}$ aggregate is a complex function of the refractive index, the number of monomers, and the monomer size. Further, they found that T-matrix computed optical properties of bare BC aggregates differ profoundly from those calculated for the respective volume-equivalent $\mathrm{BC}$ spheres and for the respective external mixtures of $\mathrm{BC}$ monomers under the assumption that there are no electromagnetic interactions between the monomers. Kahnert and Devasthale (2011) found that the radiative forcing at the top of the atmosphere is two times higher if fresh BC is modeled as an aggregate instead of a homogeneous sphere. Radiative forcing due to aggregates with open chainlike (lacy) structures is 1.1-1.6 times higher than for aggregates with a more compact shape. Adachi et al. (2010) showed that many BC particles from a mega-city have lacy shapes even after being surrounded by organic matter and that $\mathrm{BC}$ is located in off-center positions within its host material. Off-center embedded BC aggregates absorb sunlight less efficiently than if compact and located near the center of its host particle (Fuller et al., 1999). Further, Adachi et al. (2010) found that radiative forcing is $20 \%$ less when modeling internally mixed BC particles as embedded lacy aggregates than as a simple coreshell shape, which is the shape assumed in many climate models.

The impact of shape on aerosol optical properties is a relevant topic as well for interpretation of remote sensing measurements. Any retrieval approach used in analyses of radiometric and polarimetric data requires a model of aerosol particle shape, and in the majority of studies the model of spherical or randomly oriented spheroids particles has been adopted (e.g., Deuze et al., 2001; Hasekamp et al., 2011; Dubovik et al., 2010). Mishchenko and Travis (1997a,b) related the possibility of improvement of satellite aerosol retrievals with use of spectral multi-angular polarization as well as intensity of reflected sunlight. The amount of light escaping the top of the atmosphere is affected by the angle at which the light is reflected by the surface or atmosphere. The MISR sensor on the Terra satellite uses this dependency to separate the aerosol signal from that of surface reflectance and determines the aerosol properties (Kaufman et al., 2002). Polarization of the scattered sunlight is extremely sensitive to such properties of aerosols as particle 
size relative to the wavelength and refractive index, which often makes possible the retrieval of these parameters from polarimetric observations (Dlugach and Mishchenko, 2005, 2008). It is known that linear polarization is strongly dependent on particle shape (e.g., Mishchenko et al., 1996, 2002; $\mathrm{Wu}$ et al., 2012). It should therefore be expected that particle non-sphericity can affect the retrieval of aerosol microphysical characteristics, such as refractive index and size, from remote-sensing data.

This paper describes a sensitivity study on the effects of aggregation and internal mixing on optical properties of $\mathrm{BC}$, including absorption, scattering, AAE, linear polarization, scattering phase function, and others. We applied a DDA model to examine these effects for black carbon particles bare and mixed with salt - that we characterized with scanning and transmission electron microscopes. The discrete dipole approximation model presented captures complexities in particle morphology that other models do not and thus may be useful in predicting aerosol optical properties in climate modeling and interpreting data remotely measured with satellites.

\section{Methods}

\subsection{Particle generation and morphological characterization}

We generated bare $\mathrm{BC}$ and $\mathrm{BC}$ internally mixed with $\mathrm{NaCl}$. We chose $\mathrm{NaCl}$ because (i) is an atmospherically abundant inorganic compound derived from evaporated ocean water and (ii) chemical aging and atmospheric processing of sea salt particles may take place in many geographic areas where marine aerosol interacts with anthropogenic pollutants, such as BC, sulfate, and organic aerosol (Laskin et al., 2012; Li et al., 2003; Smirnov et al., 2011; Pace et al., 2006). Bare BC was generated by nebulizing and drying a stable suspension of $\mathrm{BC}$ in pure water. The $\mathrm{BC}$ was made with a non-premixed methane-air flame (Kirchstetter and Novakov, 2007). The BC from this flame has a morphology and MAC $\left(8.5 \mathrm{~m}^{2} \mathrm{~g}^{-1}\right.$ at $550 \mathrm{~nm}$ ) consistent with freshly generated soot particles (Moosmuller et al., 2009; Bond and Bergstrom, 2006). Aqueous suspensions of the flame BC were prepared after its collection on Teflon filters and exposure to ozone, which transformed the $\mathrm{BC}$ from a hydrophobic to a hydrophilic state (Chughtai, 1991), and after which the BC readily mixed with water. To generate coated $\mathrm{BC}$, we dissolved $\mathrm{NaCl}$ in the $\mathrm{BC}$ suspension and co-nebulized both species together.

The mixing state and morphology of the aerosol mixture were determined using scanning and transmission electron microscopy (SEM and TEM). SEM and TEM images provided morphological information, including aggregate shape, number and size of monomers, and state of mixing with $\mathrm{NaCl}$. We used these images to model aggregates with the same characteristics in the DDA model.

\subsection{Morphological characterization of aggregates}

BC particles can be characterized as a mass fractal, where each particle is represented as an aggregate of the same sized primary spherical particles (monomers), with the following formula

$N_{\mathrm{m}}=k_{0}\left(R_{\mathrm{g}}^{3 \mathrm{D}} / r_{\mathrm{m}}\right)^{D_{\mathrm{f}}}$,

where $N_{\mathrm{m}}$ is the number of monomers, $k_{0}$ is the prefactor (structural coefficient), $R_{\mathrm{g}}^{3 \mathrm{D}}$ is the three dimensional radius of gyration, $r_{\mathrm{m}}$ is the monomer radius, and $D_{\mathrm{f}}$ is the mass fractal dimension. Techniques involving transmission/scanning electron microscopy coupled with digital image analysis have found use in determining $D_{\mathrm{f}}$ of aggregates from their projected images. Several studies have suggested that $R_{\mathrm{g}}^{3 \mathrm{D}}$ can be extracted by measuring the projected parameter $L_{\max }^{2 \mathrm{D}}$. Brasil et al. (1999) suggested a ratio of $L_{\max }^{2 \mathrm{D}} / R_{\mathrm{g}}^{3 \mathrm{D}}=3.0 \pm 0.1$ for all $N_{\mathrm{m}}$ and overlap factors. $D_{\mathrm{f}}$ can be extracted from an empirical statistical scaling power law that relates the size of the aggregate to the ratio $L_{\max }^{2 \mathrm{D}} / r_{\mathrm{m}}$ :

$$
\begin{aligned}
\log \left(N_{\text {proj }}\right) & =\log \left(k_{0}\right)+D_{\mathrm{f}} \log \left(R_{\mathrm{g}}^{3 \mathrm{D}} / r_{\mathrm{m}}\right) \\
& =\log \left(k_{0}\right)+D_{\mathrm{f}} \log \left(L_{\max }^{2 \mathrm{D}} / 3 r_{\mathrm{m}}\right),
\end{aligned}
$$

where the projected number of monomers $\left(N_{\text {proj }}\right)$ in Eq. (2) is determined from the ratio of the aggregate projected area $A_{\text {agg }}$ to the average monomer area $A_{\mathrm{p}}$. An empirical formula relating $N_{\mathrm{m}}$ and $N_{\text {proj }}$ is proposed by Chakrabarty et al. (2011), where $N_{\mathrm{m}}$ can be corrected for an overlapping factor:

$N_{\mathrm{m}} / N_{\text {proj }}=0.46 e^{0.68 D_{\mathrm{f}}}$.

The described technique has the advantage of extracting a $D_{\mathrm{f}}$ value independent of the value assumed for $k_{0}$. The literature shows a wide range of values for $k_{0}$, and it is still under discussion which is most appropriate despite the common use of $k_{0}=1.19$ (Brasil et al., 1999; Chakrabarty et al., 2011; Adachi et al., 2007; Heinson et al., 2010). In Eq. (4), the $D_{\mathrm{f}}$ value of 1.8 has been used.

\subsection{Discrete dipole approximation model}

Using the equations above and the morphological features in SEM and TEM images, we constructed model aggregates (targets) to initialize the DDA model, DDSCAT.7 (Draine and Flatau, 1994, 2010). DDSCAT approximates a continuum medium with a finite array of dipoles with individual polarizabilities. The electromagnetic scattering problem for an incident periodic wave interacting with this array of point dipoles is then solved exactly. The principal advantage of the DDA is that it is completely flexible regarding the geometry of the particle, being limited only by the need to use an interdipole separation $d$ that satisfies the relationship $|m| k d<1$. We use $|m| k d<0.3$ to precisely determine the scattering phase function and linear polarization (Draine and Flatau, 2010), where $m$ is the refractive index of the target 
material and $k=2 \pi / \lambda$. In DDSCAT, the target effective radius, $a_{\text {eff }}$, is defined as the radius of a sphere with the same volume as the target

$a_{\text {eff }}=(3 V / 4 \pi)^{1 / 3}$

$V=N d^{3}$

where $N$ is the number of dipoles and $V$ is the volume.

The DDSCAT output variables of interest for this study are

1. the dimensionless quantity $\alpha_{i}$ with $i=(1,2,3)$ :

$$
\begin{aligned}
\alpha_{i} & =I_{\mathrm{i}} / 0.4 M a_{\mathrm{eff}}^{2} \\
M & =\rho V,
\end{aligned}
$$

where $I_{\mathrm{i}}$ is the moment of inertia tensor, $\rho$ is the density, and $V$ is the volume of the modeled aggregate. For a solid sphere, e.g., the case $S$ in our study, $\alpha_{i}=1$ with $i=(1,2,3)$.

2. The absorption, scattering and extinction efficiencies $\left(Q_{\text {abs,scat,ext }}(\lambda)\right)$ defined as

$$
Q_{\mathrm{abs}, \mathrm{scat}, \mathrm{ext}}=C_{\mathrm{abs}, \mathrm{scat}, \mathrm{ext}} / \pi a_{\mathrm{eff}}^{2} \text {, }
$$

where $C_{\text {abs,scat,ext }}(\lambda)$ are the absorption, scattering and extinction optical cross-sections.

3. The $4 \times 4$ Mueller scattering intensity matrix $\left(\mathbf{S}_{i j}\right)$ with $i, j=(1,2,3,4)$ describing the complete scattering properties of the target for specified scattering directions.

From these variables we calculated:

1. the porosity $(P)$ of the structure of modeled aggregates as defined by Shen et al. (2008):

$P=1-f$

$f=\left[\left(\alpha_{2}+\alpha_{3}-\alpha_{1}\right)\left(\alpha_{3}+\alpha_{1}-\alpha_{2}\right)\left(\alpha_{1}+\alpha_{2}-\alpha_{3}\right)\right]^{-1 / 2}$,

where $\alpha_{i}$ is defined in Eq. (7). The value of $P$ is larger for a lacy aggregate than it is for a compact aggregate. $P$ is introduced because the commonly used $D_{\mathrm{f}}$ is not a good measure of porosity and compactness.

2. The mass absorption coefficient (MAC):

$$
\begin{aligned}
& \mathrm{MAC}=C_{\mathrm{abs}} / \operatorname{mass}_{\mathrm{BC}} \\
& \operatorname{mass}_{\mathrm{BC}}=\rho \frac{4}{3} \pi a_{\mathrm{eff}}^{3},
\end{aligned}
$$

where $\rho$ is the density of $\mathrm{BC}$ and $a_{\text {eff }}$ is the effective radius.
3. The aerosol absorption Angstrom exponent (AAE) computed from the slope of the linear fit passing though MAC curves (in log-log scale):

$$
\mathrm{AAE}=\frac{-\triangle \log (\mathrm{MAC})}{\triangle \log (\lambda)},
$$

where $\mathrm{AAE}=1$ if $\mathrm{MAC} \propto \lambda$, and $\mathrm{AAE}=0$ if $\mathrm{MAC}$ is constant with wavelength. AAE is presented for three wavelength regions.

4. The single scattering albedo (SSA):

$$
\operatorname{SSA}=Q_{\text {scat }}(\lambda) / Q_{\text {ext }}(\lambda) .
$$

5. The scattering phase function $\left(S_{11}(\theta)\right)$ as the intensity $(F)$ at $\theta$ relative to the normalized integral of the scattered intensity at all angles $\left(F(\theta) / \int_{0}^{\pi} F(\theta) \sin (\theta) \mathrm{d} \theta\right)$. The scattering angle, $\theta \in[0, \pi]$, is defined as the angle between the incidence and scattering directions.

6. The degree of linear polarization $-S_{12}(\theta) / S_{11}(\theta)$.

To focus on the effects of aggregation and mixing on optical properties of $\mathrm{BC}$, refractive indices of $\mathrm{BC}$ and $\mathrm{NaCl}$ were treated as constant in the spectral range between 200 and $1000 \mathrm{~nm}$ (Moffet and Prather, 2009), where $m_{\mathrm{BC}}=1.95-$ $0.79 i$ and $m_{\mathrm{NaCl}}=1.5$. We assume the density of $\mathrm{BC} \rho_{\mathrm{BC}}=$ $1.8 \mathrm{~g} \mathrm{~cm}^{-3}$ (Bond and Bergstrom, 2006). Reported optical properties are the average values computed for 1000 random target orientations (Kahnert et al., 2012) and 9 multiple scattering planes that satisfy the condition $|m| k d<0.3$. Optical properties were also computed for 64 (according to Shen et al., 2008, 2009) and 3000 orientations.

As noted below, we found that 64 target orientations were sufficient to converge on the optical properties (i.e., MAC and SSA) of bare and internally mixed compact aggregates, but a larger number of orientations was required to attain converged orientation averaged values of the MAC of internally mixed lacy aggregates. Predicted optical properties using 1000 target orientations are consistent with results using 3000 orientations.

\section{Results}

\subsection{Uncoated BC aggregates}

The SEM images in Fig. 1 show the fractal nature of the generated bare BC. The aggregates are composed of spherical primary particles (monomers) of about the same size. The characteristics of the bare BC studied are presented in Table 1 and Fig. 2. The heterogeneity of the morphological characteristics are representative of the SEM images analyzed. Cases A through E correspond to five types of aggregates that vary in compactness (porosity), number and size 
Table 1. Characteristics of the modeled bare BC and optical properties predicted by DDSCAT.

\begin{tabular}{rrrrrrrr}
\hline Case & $\begin{array}{r}2 r_{\mathrm{m}} \\
{[\mathrm{nm}]}\end{array}$ & $N_{\mathrm{m}}$ & $\begin{array}{r}a_{\text {eff }} \\
{[\mathrm{nm}]}\end{array}$ & $P$ & $\begin{array}{r}\text { AAE } \\
(200-550 \mathrm{~nm})\end{array}$ & $\begin{array}{r}\text { AAE } \\
(288-550 \mathrm{~nm})\end{array}$ & $\begin{array}{r}\text { AAE } \\
(550-1000 \mathrm{~nm})\end{array}$ \\
\hline $\mathrm{A}$ & 40 & 70 & 82 & 0.84 & 0.86 & 0.89 & 0.96 \\
$\mathrm{~B}$ & 30 & 64 & 60 & 0.80 & 0.83 & 0.90 & 1.04 \\
$\mathrm{C}$ & 40 & 70 & 82 & 0.72 & 0.78 & 0.82 & 0.90 \\
$\mathrm{D}$ & 40 & 100 & 100 & 0.92 & 0.82 & 0.92 & 0.96 \\
$\mathrm{E}$ & 40 & 100 & 100 & 0.80 & 0.62 & 0.73 & 0.86 \\
$\mathrm{~S}$ & $\mathrm{~N} / \mathrm{A}$ & $\mathrm{N} / \mathrm{A}$ & 100 & 0 & 0.08 & 0.01 & 1.04 \\
\hline
\end{tabular}

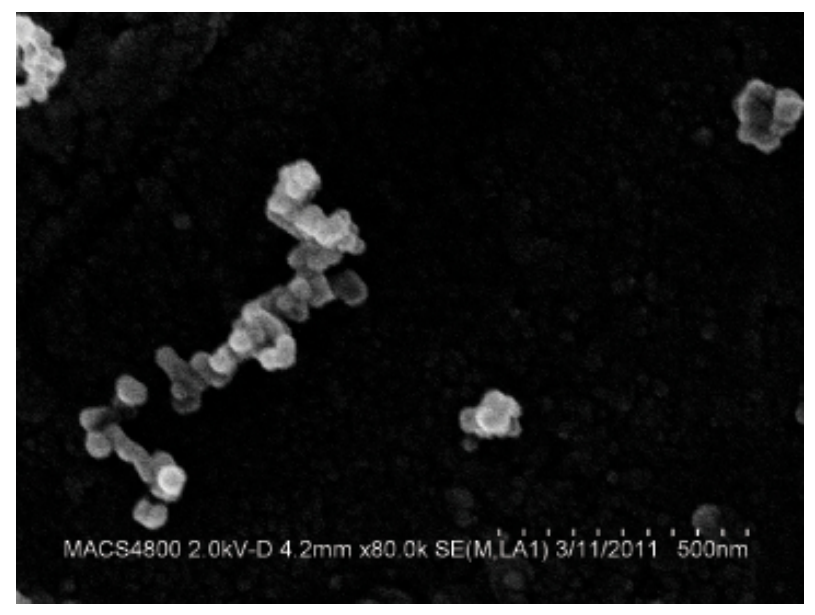

(a)

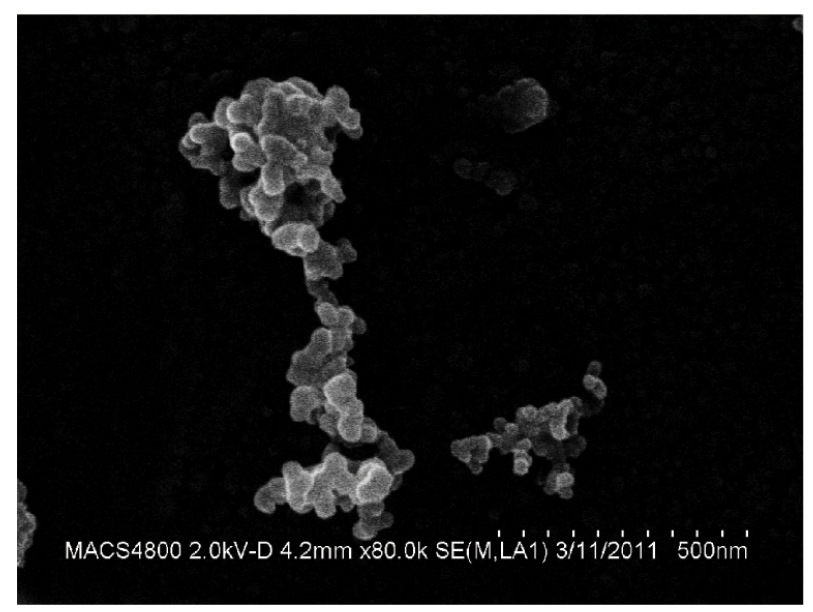

(b)

Fig. 1. Two SEM images of bare BC aggregates. In each image, two types of morphologies are evident: chain-like (lacy) structures and compact structures.

of monomers. Case $\mathrm{S}$ is a homogeneous sphere approximation (HSA). Optical properties are compared for cases A and $\mathrm{C}$, and cases $\mathrm{D}, \mathrm{E}$ and $\mathrm{S}$, which have the same number and size of monomers and/or effective radius but different porosities. Case B presents, instead, a smaller size and number of monomers.

Predicted values of MAC are shown in Fig. 3a for a composite of aggregates. At wavelengths smaller than $550 \mathrm{~nm}$, MAC values depend on the morphology of the $\mathrm{BC}$ aggregate. The MAC curves separate in this wavelength range as a result of the dependency between the size of the particle and the incident radiation wavelength. For larger bare $\mathrm{BC}$ aggregates, the separation starts at longer wavelengths. (This is also evident in the case of larger coated BC aggregates, as shown in Fig. 7a).

Generally, MAC is higher for smaller aggregates (with lower mass). Higher MAC values are found for lacy aggregates compared to more compact structures (compare cases A vs. C and D vs. E). This general behavior was also found by Liu et al. (2008) and Kahnert and Devasthale (2011).

Compared to aggregates (cases D and E), the homogeneous sphere approximation (HSA, case S) exhibits significantly lower MAC below $550 \mathrm{~nm}$ and slightly higher MAC in the Rayleigh regime $(550-1000 \mathrm{~nm})$. In all cases, MAC lies between 6.3 and $7.0 \mathrm{~m}^{2} \mathrm{~g}^{-1}$ at $550 \mathrm{~nm}$, in agreement with the range of values reported by Bohren and Huffman (1983); Martins et al. (1998); Fuller et al. (1999); Bergstrom (1973); Bond and Bergstrom (2006); Adachi et al. (2007).

For aggregates with a much larger number of monomers (600) than those modeled in this study, Kahnert (2010b) estimated MAC values (at $550 \mathrm{~nm}$ ) of $5.2 \pm 0.1 \mathrm{~m}^{2} \mathrm{~g}^{-1}$ for lacy aggregates, $4.9 \pm 0.1 \mathrm{~m}^{2} \mathrm{~g}^{-1}$ for compact aggregates, and $3.3 \pm 0.4 \mathrm{~m}^{2} \mathrm{~g}^{-1}$ for spheres. These lower values are likely the result of the large number of aggregate monomers (see Eq. 12) where compact aggregates have a low porosity.

The variation in absorption with wavelength does not adhere precisely to a power law relationship over the 200 to $1000 \mathrm{~nm}$ range. Consequently, computed AAE values depend on the wavelength range considered. As shown in Table 1, AAE values computed between 288 and $550 \mathrm{~nm}(0.73-0.92)$ are smaller than those computed between 550 and $1000 \mathrm{~nm}$ (0.86 to 1.04). AAE values of $\simeq 1$ in the Rayleigh regime (550-1000 nm) are consistent with observations (e.g., Russell et al., 2010) and other theoretical results (Bohren and Huffman, 1983; Bergstrom, 1973). 

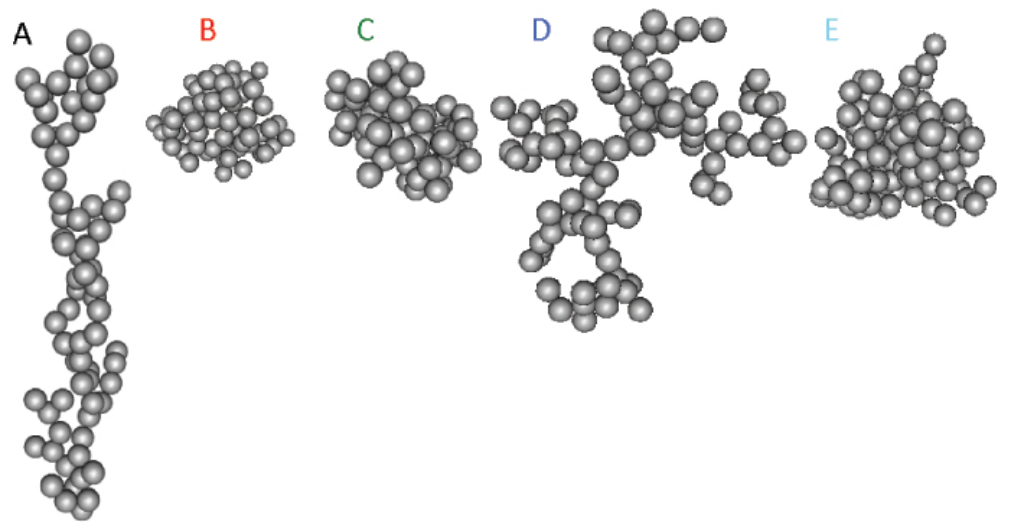

Fig. 2. Visual representation of modeled bare BC. The labels A-E are color coded to match the legends in Fig. 3. Case A is a lacy structure of 70 monomers with diameters of $40 \mathrm{~nm}$. Case B is a compact structure of 64 monomers with diameters of $30 \mathrm{~nm}$. Case C is a compact version of case A. Cases D and E are aggregates of 100 monomers with diameters of $40 \mathrm{~nm}$, but with different compactness.

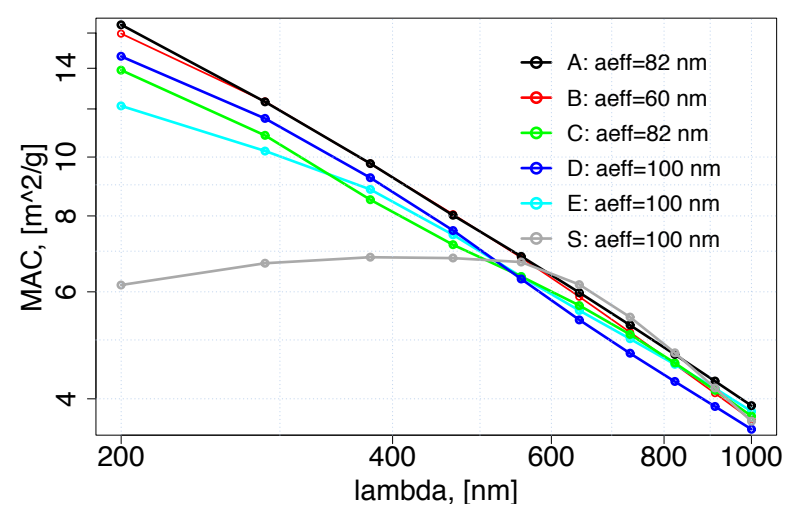

(a) MAC for bare BC

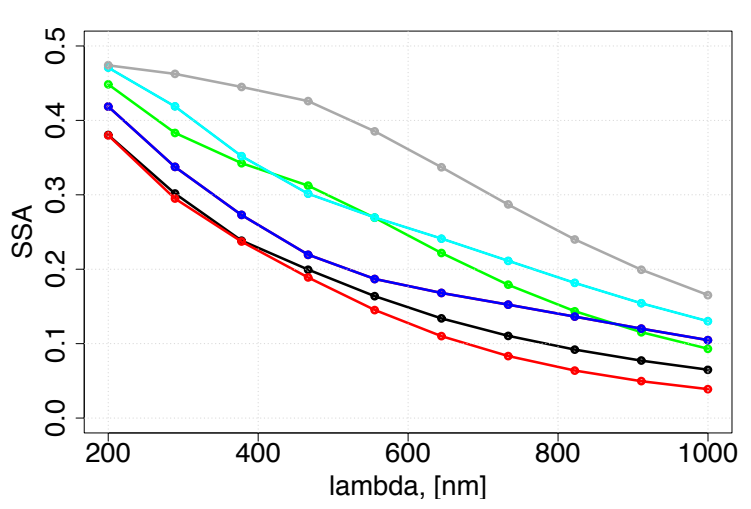

(b) SSA for bare BC

Fig. 3. (a) MAC in log-log scale and (b) SSA for five bare BC aggregates (cases A-E) and one homogeneous sphere approximation with equivalent volume of case D and E (HSA, case S). For a fixed number of the same sized monomers, compact aggregates exhibit lower MAC and higher SSA than lacy aggregates. All the computed optical values are averaged over 1000 target orientations and 9 scattering planes and satisfy the condition $|m| k d<0.3$. We use $m_{\mathrm{BC}}=1.95-0.79 i$ and $\rho_{\mathrm{BC}}=1.8 \mathrm{~g} \mathrm{~cm}^{-3}$. The spectral resolution is $100 \mathrm{~nm}$. The characteristics of the bare $\mathrm{BC}$ are described in Table 1 and Fig. 2.

Predicted values of AAE were sensitive to aggregate compactness and monomer size. Compact aggregates exhibited lower AAE values than lacy aggregates (compare cases A vs. $C$ and cases $D$ vs. E). Compact aggregates with the same monomer diameter (cases $\mathrm{C}$ and $\mathrm{E}$ ), while having different aggregate size, have lower AAEs than the aggregate with smaller diameter monomers (case B). AAE values are also different for aggregates with the same porosity (cases B and E) but with different numbers of differently sized monomers.

Predicted values of SSA are shown in Fig. 3b. Values of SSA are higher for compact aggregates than for lacy aggregates (compare cases D vs. E and A vs. C), in agreement with Kahnert and Devasthale (2011). Compact aggregates are characterized by a higher scattering cross section than lacy aggregates, also found by Liu et al. (2008), due to a stronger scattering interaction and stronger electromagnetic coupling between spherules. The SSA values for BC aggregates and the homogeneous sphere (HSA) differ markedly (compare cases D, E and S). The $550 \mathrm{~nm}$ SSA for BC aggregates ranges between 0.16 and 0.27 as a function of compactness and size of the aggregate, in agreement with the suggested value of $0.25 \pm 0.05$ (Kahnert, 2010b; Fuller et al., 1999), while a much higher SSA of 0.39 is predicted for the HSA case.

It is noteworthy that, for the size of particles presented here, MAC values are sensitive to particle shape only at short wavelengths where incoming solar radiation is weak (due to absorption of the ozone layer). On the other hand, the scattering coefficients are sensitive to particle shape over the full solar spectrum. As a result, aerosol SSA, and thus aerosol radiative forcing, is sensitive to particle shape. Further, SSA is retrieved from remote sensing data, where retrieval algorithms approximate particles as having homogeneous 


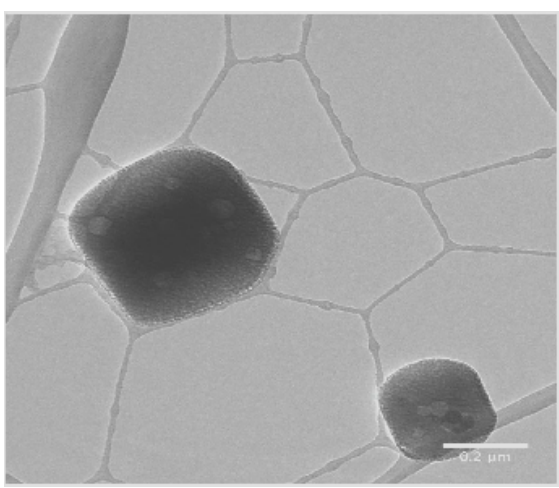

(a) $\mathrm{BC}$ immersion in $\mathrm{NaCl}$

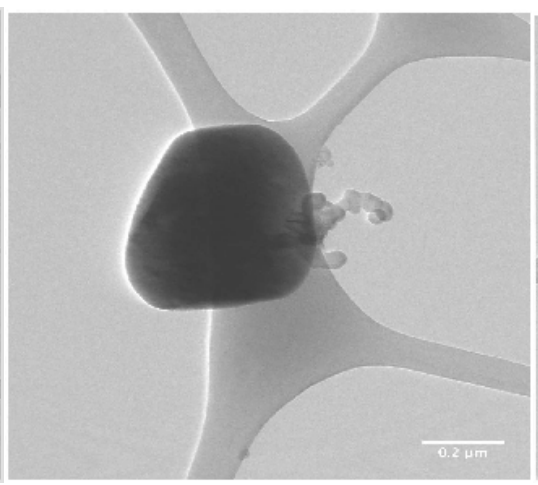

(b) BC immersion in and surface contact with $\mathrm{NaCl}$

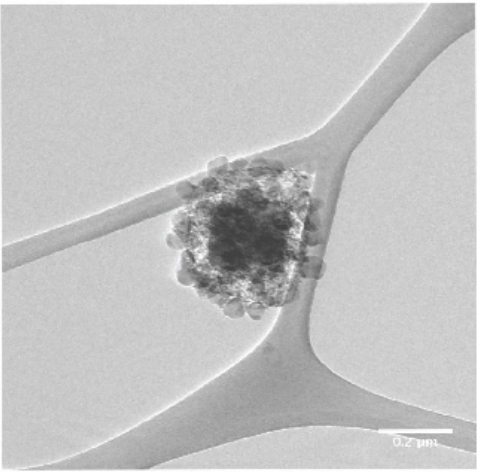

(c) $\mathrm{NaCl}$ immersion in $\mathrm{BC}$

Fig. 4. TEM images of $\mathrm{BC}$ (lighter grey) mixed with $\mathrm{NaCl}$ (darker grey): (a) total inclusion of $\mathrm{BC}$ in $\mathrm{NaCl}$, (b) partial inclusion and partial surface contact of $\mathrm{BC}$ in $\mathrm{NaCl}$, and (c) total inclusion of $\mathrm{NaCl}$ in $\mathrm{BC}$.

Table 2. Characteristics of the modeled bare $\mathrm{BC}$ and mixtures of $\mathrm{BC}$ and $\mathrm{NaCl}$ and optical properties predicted by DDSCAT. The core $\mathrm{BC}$ has 70 monomers with diameter of $40 \mathrm{~nm}$.

\begin{tabular}{|c|c|c|c|c|c|c|c|}
\hline Cases & $\begin{array}{r}a_{\text {eff }} \\
{[\mathrm{nm}]}\end{array}$ & $P$ & $\begin{array}{r}V_{\mathrm{NaCl}} / V_{\mathrm{BC}} \\
\left(a_{\mathrm{eff}, \text { shell }} / a_{\mathrm{eff}, \text { core }}\right)\end{array}$ & $\begin{array}{r}\text { AAE } \\
(200-550 \mathrm{~nm})\end{array}$ & $\begin{array}{r}\text { AAE } \\
(288-550 \mathrm{~nm})\end{array}$ & $\begin{array}{r}\text { AAE } \\
(550-1000 \mathrm{~nm})\end{array}$ & MAC $(550)_{\text {mixture }} / \operatorname{MAC}(550)_{\text {bare }}$ \\
\hline $\mathrm{F}$ & 82 & 0.86 & - & 0.92 & 0.92 & 0.93 & - \\
\hline G & 82 & 0.60 & - & 0.58 & 0.68 & 0.93 & - \\
\hline FI & 303 & & $50(3.7)$ & 0.60 & 0.70 & 1.01 & 1.7 \\
\hline GI & 199 & & $9.17(2.42)$ & 0.42 & 0.51 & 1.28 & 2.4 \\
\hline FIS & 138 & & $4.47(1.68)$ & 0.89 & 0.80 & 0.89 & 1.0 \\
\hline GIS & 110 & & $0.84(1.34)$ & 0.38 & 0.52 & 1.12 & 1.5 \\
\hline
\end{tabular}

spherical or spheroidal shape (Dubovik et al., 2006; Mischenko et al., 2000). Given the sensitivity of computed values of SSA to BC shape approximation (sphere or aggregate of spheres) and aggregate porosity (shown in Fig. 3b), ambiguities in aerosol composition or mixtures retrieved may be expected.

\section{2 $\mathrm{BC}$ internally mixed with $\mathrm{NaCl}$}

The TEM images in Fig. 4 illustrate different types of internal mixing: (a) total inclusion of $\mathrm{BC}$ in a $\mathrm{NaCl}$ particle, (b) partial inclusion and partial surface contact of $\mathrm{BC}$ on the $\mathrm{NaCl}$ surface, and (c) inclusion of $\mathrm{NaCl}$ in a larger $\mathrm{BC}$ aggregate. SEM images of aerosol samples from field campaigns, including the second Aerosol Characterization Experiment ( $\mathrm{Li}$ et al., 2003) and the Carbonaceous Aerosol and Radiative Effects Study (Laskin et al., 2012), show sea salt aerosol with a smoothed cubic/rectangular prism shape, internal mixtures of $\mathrm{NaCl}$ with $\mathrm{BC}$ aggregates, and $\mathrm{NaCl} / \mathrm{BC}$ mixtures with features similar to those observed in our samples, with a partial inclusion and partial surface contact of $\mathrm{BC}$ on the $\mathrm{NaCl}$ surface (Fig. 4b). As indicated in Table 2 and Figs. 5 and 6, we simulated these different possibilities: two cases of complete $\mathrm{BC}$ inclusion in $\mathrm{NaCl}$ (cases FI and GI) and two cases of $\mathrm{BC}$ inclusion and surface contact of $\mathrm{BC}$ on $\mathrm{NaCl}$ (FIS and GIS). For comparison, we also modeled two cases (F and G) of lacy and compact $\mathrm{BC}$ aggregates in bare condition (i.e., not mixed with $\mathrm{NaCl}$ ).

Predicted values of MAC are shown in Fig. 7a. Compared to bare $\mathrm{BC}$ aggregates, the MAC of $\mathrm{BC}$ mixed with $\mathrm{NaCl}$ can be substantially larger, depending on the extent of mixing and $\mathrm{BC}$ morphology. Absorption amplification factors computed as $\operatorname{MAC}(\lambda)_{\text {mixture }} / \operatorname{MAC}(\lambda)_{\text {bare }}$ at $\lambda=550 \mathrm{~nm}$ are listed in Table 2. We also computed absorption amplification factors averaged over the $200-1000 \mathrm{~nm}$ range, which were $1.0 \pm 0.0$ for lacy $\mathrm{BC}$ aggregates partially included in $\mathrm{NaCl}$ (case FIS), $1.7 \pm 0.1$ for lacy BC aggregates fully included in $\mathrm{NaCl}$ (case FI), $1.4 \pm 0.1$ for compact BC with an inclusion of $\mathrm{NaCl}$ (case GIS) and 2.2 \pm 0.2 for compact $\mathrm{BC}$ aggregates fully immersed in $\mathrm{NaCl}$ (case GI).

The amplification factors stated above correspond to optical properties averaged over 1000 target orientations. Amplification factors computed using 3000 target orientations were the same. Amplification factors computed using 64 target orientations were the same as those stated above for compact BC aggregates (cases GIS and GI), but were slightly higher for lacy BC aggregates: $1.1 \pm 0.0$ for case FIS and $2.0 \pm 0.1$ for case FI. This illustrated the significance of using 


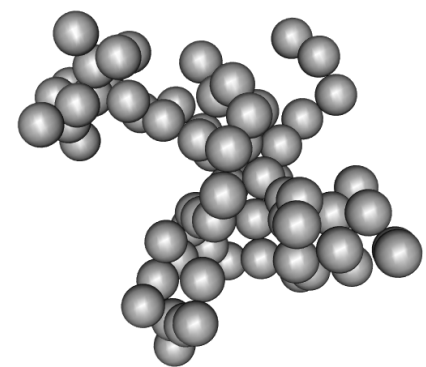

(a) Bare lacy $B C(F)$

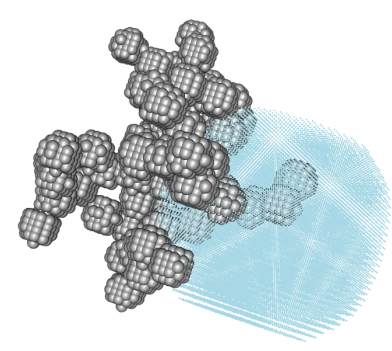

(b) BC partial immersion and partial surface contact on $\mathrm{NaCl}$ crystal (FIS)

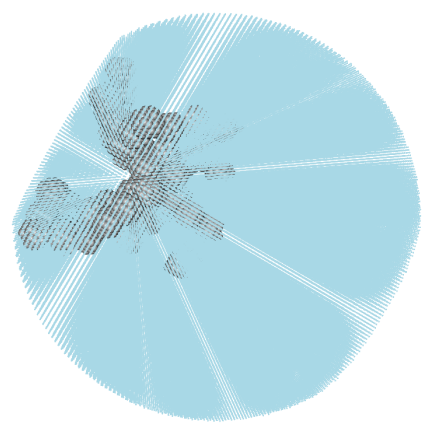

(c) $\mathrm{BC}$ immersion in $\mathrm{NaCl}(\mathrm{FI})$

Fig. 5. Visual representation of modeled internal mixtures of lacy $\mathrm{BC}$ aggregates and $\mathrm{NaCl}$. (a) Case $\mathrm{F}$ is a bare lacy $\mathrm{BC}$ aggregate. (b) Case FIS shows a BC partial immersion and partial surface contact on $\mathrm{NaCl}$ crystal, while (c) case FI is a total inclusion of $\mathrm{BC}$ (lighter grey) in salt particle (light blue). The points in light blue are the dipoles representing $\mathrm{NaCl}$, while the circles in light grey represent the dipole positions for $\mathrm{BC}$. The dense number of dipoles finely characterizes the morphology of $\mathrm{NaCl}$ and of the $\mathrm{BC}$ aggregate.

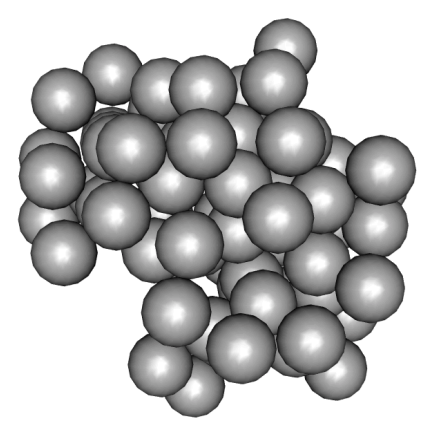

(a) Bare compact $B C(G)$

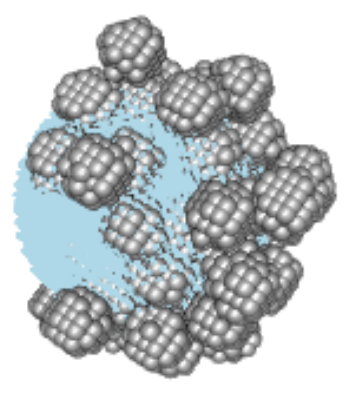

(b) $\mathrm{NaCl}$ immersion in $\mathrm{BC}(\mathrm{GIS})$

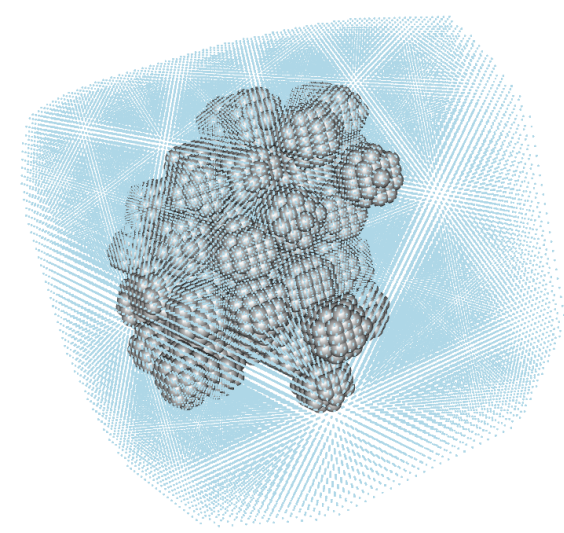

(c) BC immersion in $\mathrm{NaCl}(\mathrm{GI})$

Fig. 6. Visual representation of modeled internal mixtures of compact $\mathrm{BC}$ aggregates and $\mathrm{NaCl}$. (a) Case $\mathrm{G}$ is a bare compact $\mathrm{BC}$ aggregate. (b) Case GIS shows a compact $\mathrm{BC}$ with an "inclusion" of $\mathrm{NaCl}$, while (c) case $\mathrm{GI}$ is a total inclusion of BC (lighter grey) in salt particle (light blue). The points in light blue are the dipoles representing $\mathrm{NaCl}$, while the circles in light grey represent the dipole positions for $\mathrm{BC}$. The dense number of dipoles finely characterizes the morphology of $\mathrm{NaCl}$ and of the $\mathrm{BC}$ aggregate.

a sufficient number of target orientations to converge on predicted optical properties using DDSCAT.

The compactness of the BC aggregate influenced the MAC of $\mathrm{BC}-\mathrm{NaCl}$ mixtures. Higher MAC amplification factors are found for internally mixed compact $\mathrm{BC}$ (with even less coating amounts) than for internally mixed lacy BC. Compared to bare $\mathrm{BC}$, the MAC of the mixtures increased because (i) BC is surrounded by $\mathrm{NaCl}$, which has a larger refractive index than the surrounding bulk medium (air) (Bohren, 1986; Flanner et al., 2012) and (ii) light is internally reflected in the nonabsorbing $\mathrm{NaCl}$ (Fuller et al., 1999). Additionally, radiation is focused near the center of the particle, enabling further absorption enhancement from inclusions that happen to reside near the center of the mixture. Bohren (1986) and Adachi et al. (2010) also discuss the effect of the position of BC in a host material.

In the 550 to $1000 \mathrm{~nm}$ region, the AAE for coated particles increases as $\mathrm{BC}$ becomes increasingly embedded in $\mathrm{NaCl}$. In the region between 200 and $550 \mathrm{~nm}$, AAE decreases when the embedding of $\mathrm{BC}$ in $\mathrm{NaCl}$ increases (see Table 2). As with bare $\mathrm{BC}$, the $\mathrm{AAE}$ of $\mathrm{BC}$ internally mixed with $\mathrm{NaCl}$ is smaller in the 200 to $550 \mathrm{~nm}$ range than in the 550 to $1000 \mathrm{~nm}$ range.

Predicted values of SSA are shown in Fig. 7b. The mixing of $\mathrm{BC}$ with $\mathrm{NaCl}$ amplifies both absorption and scattering, but scattering increases more than absorption and, therefore, SSA increases. For the cases studied, SSA tends to decrease at wavelengths below $400 \mathrm{~nm}$. This feature is a characteristic of the size of this aerosol mixture, and it is also a feature 


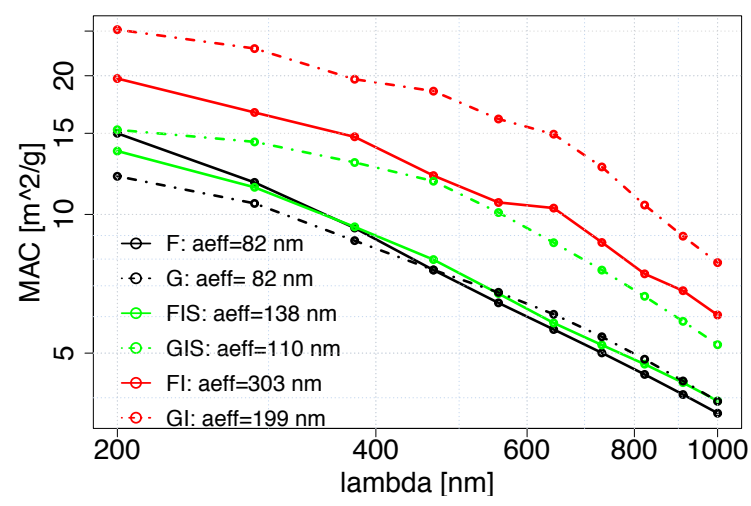

(a) MAC for bare and internally mixed BC aggregates

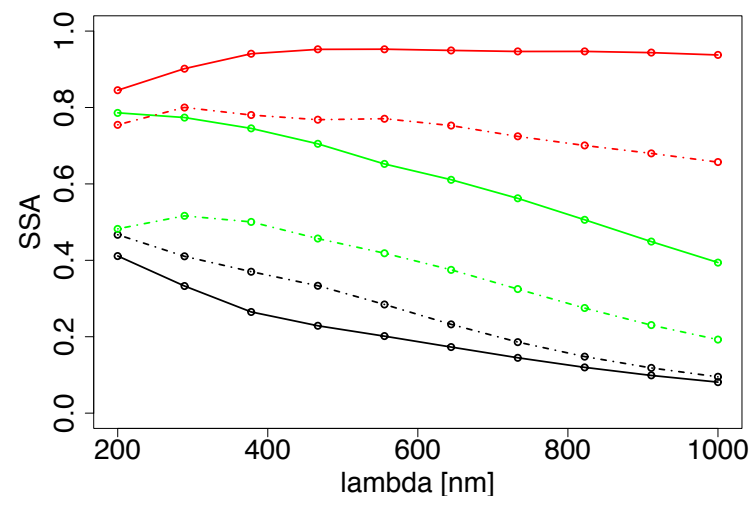

(b) SSA for bare and internally mixed BC aggregates

Fig. 7. (a) MAC in log-log scale and (b) SSA for different of bare $\mathrm{BC}$ and $\mathrm{BC}$ mixed with $\mathrm{NaCl}$ (see Table 2 and Figs. 5, and 6). The refractive index $(m)$ of $\mathrm{BC}$ and $\mathrm{NaCl}$ has been considered constant in the spectral range between 200 and $1000 \mathrm{~nm}$, where $m_{\mathrm{BC}}=1.95-0.79 i$ and $m_{\mathrm{NaCl}}=1.5$ and the density of $\mathrm{BC}\left(\rho_{\mathrm{BC}}\right)$ is $1.8 \mathrm{~g} \mathrm{~cm}^{-3}$. All the computed optical values are averaged over 1000 particle orientations and satisfy the condition $|m| k d<0.3$. The spectral resolution is $100 \mathrm{~nm}$.

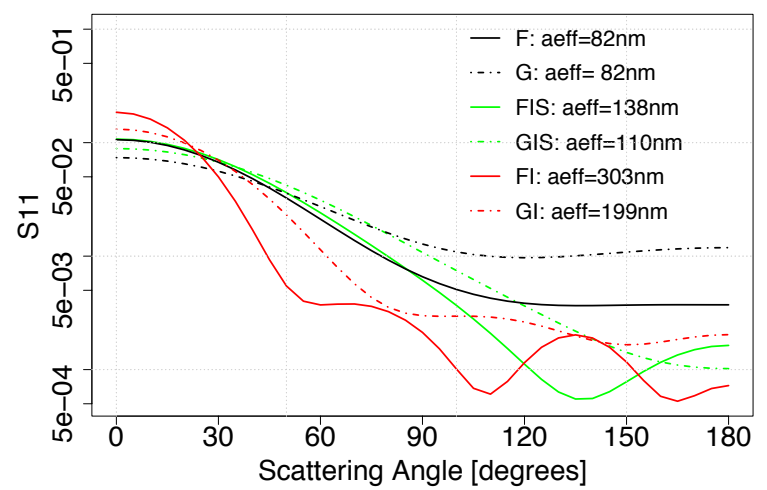

(a) S11 at $466 \mathrm{~nm}$

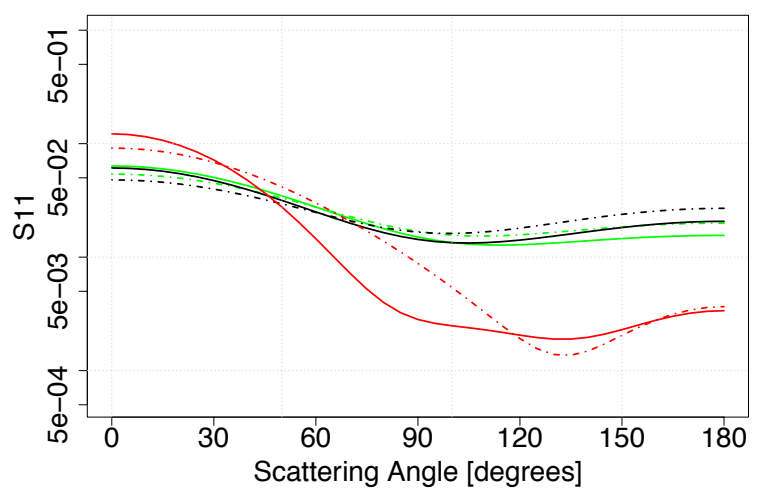

(b) S11 at $733 \mathrm{~nm}$

Fig. 8. Scattering phase function at $466 \mathrm{~nm}$ (a) and $733 \mathrm{~nm}$ (b). Characteristics of the bare $\mathrm{BC}$ (cases $\mathrm{F}$ and $\mathrm{G}$ ) and mixed $\mathrm{BC}-\mathrm{NaCl}$ (cases FI, GI, FIS, and GIS) are described in Table 2 and Figs. 5, and 6. A scattering angle of 0 degrees corresponds to radiation that is scattered in the forward direction (i.e., in the same direction as the incident radiation). A scattering angle of 180 degrees is backscattering. The coated aggregates are departing from the Rayleigh regime, and therefore display some angular variation, with forward scattering increasing.

common to the optical properties of dust and organics (Russell et al., 2010).

\subsection{Scattering phase function and polarization}

Scattering phase functions at 466 and $733 \mathrm{~nm}$ for bare and coated BC are presented in Fig. 8. The phase function describes how much light is scattered in each direction. The peak of the scattering phase function is connected to the size of the particle, where an increase in particle size leads to an increase in forward scattering. As shown in Fig. 8, the phase function also depends on aggregate compactness and mixing state. The phase function of lacy BC (case F) has a narrower and stronger forward scattering peak than that of compact BC (case G). At both 466 and $773 \mathrm{~nm}$, forward scattering increases when $\mathrm{BC}$ is totally embedded in $\mathrm{NaCl}$ (compare case
F with FI and case G with GI). This effect is much less pronounced when $\mathrm{BC}$ is only partially embedded (compare case $F$ with FIS and case $G$ with GIS). At $466 \mathrm{~nm}$, increasing the mixing of $\mathrm{BC}$ with $\mathrm{NaCl}$ reduces the phase function in the backscattering direction (compare case F with FI and FIS and case $\mathrm{G}$ with GI and GIS). At $733 \mathrm{~nm}$, scattering phase functions are similar (despite the difference in size) for bare $\mathrm{BC}$ and $\mathrm{BC}$ particles that are not fully embedded in $\mathrm{NaCl}$ (cases $\mathrm{F}$ and FIS and cases G and GIS), and a marked reduction in backscatter is evident only when BC is completely embedded in $\mathrm{NaCl}$ (cases FI and GI).

The degree of linear polarization, $-S_{12}(\theta) / S_{11}(\theta)$, is shown in Fig. 9. Perfectly polarized radiation has a degree of linear polarization equal to 1 , whereas unpolarized radiation has a degree of linear polarization equal to 0 . At 466 and 


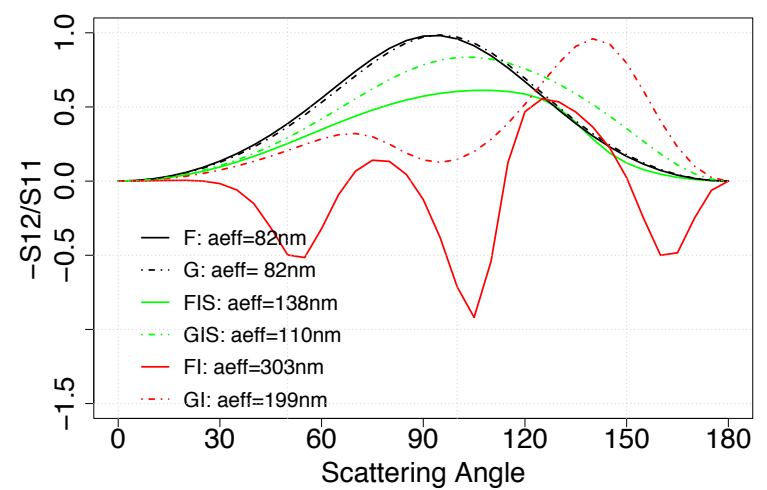

(a) $\frac{-S 12(\theta)}{S 11(\theta)}$ at $466 \mathrm{~nm}$

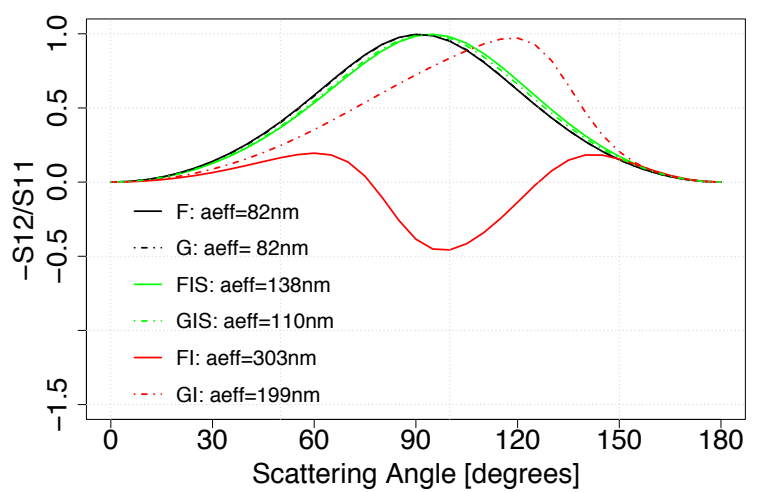

(b) $\frac{-S 12(\theta)}{S 11(\theta)}$ at $733 \mathrm{~nm}$

Fig. 9. Degree of linear polarization at $466 \mathrm{~nm}$ (a) and $733 \mathrm{~nm}$ (b). Characteristics of the bare $\mathrm{BC}$ (cases $\mathrm{F}$ and $\mathrm{G})$ and mixed $\mathrm{BC}-\mathrm{NaCl}(\mathrm{cases}$ FI, GI, FIS, and GIS) are described in Table 2 and Figs. 5, and 6.

$733 \mathrm{~nm}$, the particles with $a_{\text {eff }}$ between 82 and $130 \mathrm{~nm}$ exhibit bell shape curves (Rayleigh regime), whereas larger particles closer to the radiation wavelength present multiple modes including a negative degree of polarization at different angles. This complex structure is characteristic of Mie scattering and due to interferences of partial waves originating from different spatial regions inside the particle (i.e., different scattering angles) (Tyynelae et al., 2007). The negative sign of degree of linear polarization indicates that the scattered light is polarized parallel to the reference plane, whereas a positive degree of polarization indicates that the light is polarized perpendicular to the reference plane. At $773 \mathrm{~nm}$, negative polarization features are evident only for the lacy BC completely embedded in $\mathrm{NaCl}$ (case FI with $a_{\text {eff }}=303 \mathrm{~nm}$ ), where $-S_{12}(\theta) / S_{11}(\theta)$ shows a negative degree of polarization between 80 and 120 degrees. The case GI presents a bell shaped curve with a peak at 120 instead of 90 degrees. At shorter wavelengths, when the size of the particle and wavelengths are more comparable, $-S_{12}(\theta) / S_{11}(\theta)$ shows more complicated features (resonances) than at $773 \mathrm{~nm}$, with a negative degree of polarization starting at smaller angles (i.e., for the case FI).

\section{Summary and discussion}

In this study, models of bare $\mathrm{BC}$ and $\mathrm{BC}$ internally mixed with $\mathrm{NaCl}$ were developed based on SEM and TEM images, and optical properties including MAC, AAE, SSA, scattering phase function, and polarization were predicted over the 200 to $1000 \mathrm{~nm}$ range using DDSCAT, which applies the discrete dipole approximation (DDA). DDA is applicable to particles with arbitrary shape and anisotropic composition, which allows computation of optical properties of particles with complex chemistry and morphology, whereas other approaches require unrealistic simplifications such as averaging the re- fractive indexes of mixed composition particles (like the effective medium theory).

Key results include the following: (i) lacy aggregates have a higher MAC and lower SSA than compact aggregates, which is consistent with other modeling studies. (ii) Computed MAC are consistent with measured values of $7.5 \pm$ $1.2 \mathrm{~m}^{2} \mathrm{~g}^{-1}$. The amplification factors of MAC attributed to the mixing of $\mathrm{BC}$ with $\mathrm{NaCl}$ vary from 1.0 to 2.4 depending on the position of the $\mathrm{BC}$ aggregate in the $\mathrm{NaCl}$ and the compactness of the $\mathrm{BC}$ aggregate. Higher amplification factors are found for compact aggregates completely embedded in $\mathrm{NaCl}$. (iii) The variation in absorption with wavelength does not adhere precisely to a power law relationship over the 200 to $1000 \mathrm{~nm}$ range. Consequently, the AAE depends on the wavelength range over which it is computed. The AAE of bare $\mathrm{BC}$ aggregates is sensitive to the level of compactness and monomer size, with smaller values for compact rather than lacy aggregates. (iv) SSA values are strongly sensitive to the particle shape approximation and porosity. Further, computed values of SSA at $550 \mathrm{~nm}$ range between 0.16 and 0.27 for lacy and compact aggregates, respectively, in agreement with reported experimental values of $0.25 \pm 0.05$. The SSA of $\mathrm{BC}$ internally mixed with $\mathrm{NaCl}(100-300 \mathrm{~nm}$ in radius) is higher than for bare $\mathrm{BC}$ and increases with embedding in $\mathrm{NaCl}$. The SSA (of internally mixed BC) decreases in the 200-400 nm wavelength range, a feature also typical of the optical properties of dust and organics. (v) The linear polarization of scattered sunlight is strongly dependent on particle size and shape. Bare BC (with a radius of $80 \mathrm{~nm}$ ) presents in the linear polarization a bell shape feature, which is a characteristic of the Rayleigh regime. When $\mathrm{BC}$ is internally mixed with $\mathrm{NaCl}$ (100 and $300 \mathrm{~nm}$ in radius), the linear polarization presents complex features characteristic of Mie scattering.

In radiative transfer calculations that are used to interpret space or ground-based observations, various assumptions are made regarding the aerosol optical properties. It is common 
to approximate aerosol shape as homogeneous spherical or spheroidal particles, ignoring the effect of realistic morphology and mixing with other aerosol compounds. The results of this study indicate that there are significant differences in the optical properties of $\mathrm{BC}$ when modeled as an aggregate compared to the equivalent volume sphere (HSA), and in the optical properties of bare BC and internally mixed BC. Therefore, assuming spherical instead of irregularly shaped particles in radiative transfer calculations can lead to significant errors in retrieved parameters, such as the aerosol type, optical thickness, particles size distributions, and composition (see Dlugach and Petrova, 2003 for a complete discussion of errors). Similarly, the SSA of BC coated with $\mathrm{NaCl}$ exhibits features that are common to the optical properties of dust and organics, which could be misleading when inferring aerosol composition from measurements of SSA. Lastly, since Jacobson (2000) and others have demonstrated that BC mixing state strongly influences radiative forcing, deriving optical properties that are consistent with the complex morphology and mixing state of aerosols is warranted. The DDA model employed in this study, which has not yet been widely applied in climate assessments, may prove useful in addition to other more widely used models.

Acknowledgements. The authors are grateful to Jeffrey Cuzzi, Patrick Hamill, Bob Bergstrom and Diane Wooden for the valuable scientific discussion, and further to Luca Scarnato for suggesting reference-standard algorithms and graphical tools for image processing. We thank Jeffery Aguiar for providing the TEM images in Fig. 4 and Anthony Strawa for providing the access to the SEM at NASA Ames. The authors thank the referees for providing constructive comments and help in improving the contents of this paper.

The source of the DDSCAT code is available at the website http: //www.astro.princeton.edu/ $\sim$ draine/.

This research was supported by an appointment to the NASA Postdoctoral Program at Ames Research Center, administrated by Oak Ridge Associated Universities through a contract with NASA, and by the Radiation Sciences Program in the Earth Science Division of the Science Mission Directorate, National Aeronautical and Space Administration via award NNH09AK98I.

Edited by: N. Riemer

\section{References}

Adachi, K., Chung, S., and Busek, F.: Fractal parameters of individual soot particles determinated using electron tomography: implications for optical properties, J. Geophys. Res., 112, 827-849, 2007.

Adachi, K., Chung, S., and Buseck, P. R.: Shapes of soot aerosol particles and implications for their effects on climate, J. Geophys. Res., 115, D15206, doi:10.1029/2009JD012868, 2010.

Bergstrom, R.: Extinction and Absorption Coefficients of the Atmospheric Aerosol as a Function of Particle Size, Contr. Atmos. Phys., 46, 223-234, 1973.
Bohren, C.: Applicability of effective medium theories to problems of scattering and absorption by nonhomogenous atmospheric particles, J. Atmos. Sci., 43, 468-475, 1986.

Bohren, C. F. and Huffman, D. R.: Absorption and Scattering of Light by Small Particles., John Wiley and Sons, New York, NY, USA, 1983.

Bond, T. and Bergstrom, R. W.: Light Absorption by Carbonaceous Particles: An investigative Review, Aerosol Sci. Tecnol., 40, 2767, 2006.

Bond, T. and Mikhailov, E.: Can reducing black carbon emissions counteract global warming?, Environ. Sci. Technol., 39, 59215926, 2005.

Bond, T., Streets, D., Yarber, K., and Nelson, S.: A technology based inventory of black and organic carbon emissions from combustion, J. Geophys. Res., 108, 8823, doi:10.1029/2002JD003117, 2004.

Brasil, A. M., Farias, T. L., Carvalho, M. G., and Koylu, U. O.: A Recipe for Image characterization of Fractal-Like Aggregates, J. Aerosol Sci., 30, 1379-1389, 1999.

Bruggeman, D.: Berechnung verschiedener physikalischer konstanten von heterogenen substanzen, Ann. Phys. (Leipzig), 636-679, 1935.

Bueno, P. A., Havey, D. K., Mulholland, G. W., Hodges, J. T., Gillis, K. A., Dickerson, R. R., and Zachariah, M. R.: Photoacoustic Measurements of Amplification of the Absorption Cross Section for Coated Soot Aerosols, Aerosol Sci. Technol., 45, 1217-1230, doi:10.1080/02786826.2011.587477, 2011.

Chakrabarty, R., Garroab, M., Garroabc, B., Chancellorab, S., Moosmullerab, H., and Herald, C.: Simulation of Aggregates with Point-Contacting Monomers in the ClusterDilute Regime. Part 1: Determining the Most Reliable Technique for Obtaining Three-Dimensional Fractal Dimension from Two-Dimensional Images, Aerosol Sci. Tech., 45, 75-80, doi:10.1080/02786826.2010.520363, 2011.

Chughtai, A. E. A.: Spectroscopic and solubility characteristics of oxidized soot, Aerosol Sci. Tech., 15, 112-126, 1991.

Deuzé, J. L., Bréon, F. M., Devaux, C., Goloub, P., Herman, M., Lafrance, B., Maignan, F., Marchand, A., Nadal, F., Perry, G., and Tanré, D.: Remote sensing of aerosols over land surfaces from polder-adeos-1 polarized measurements, J. Geophys. Res., 106, 4913-4926, doi:10.1029/2000JD900364, 2001.

Dlugach, J. and Mishchenko, M.: Photopolarimetry of planetary atmospheres: what observational data are essential for a unique retrieval of aerosol microphysics?, Mon. Not. R. Astron. Soc., 384, 64-70, 2008.

Dlugach, Z. and Petrova, E.: Polarimetry of mars in hightransparency periods: How reliable are the estimates of aerosol optical properties?, Solar System Res., 37, 87-100, 2003.

Dlugach, Z. M. and Mishchenko, M. I.: The effect of aerosol shape in retrieving optical properties of cloud particles in the planetary atmospheres from the photopolarimetric data. jupiter, Solar Syst. Res., 39, 102-111, doi:10.1007/s11208-005-0026-1, 2005.

Draine, B. and Flatau, P. J.: Discrete dipole approximation for scattering calculations, J. Opt. Soc. Am. A, 11, 1491-1499, 1994.

Draine, B. and Flatau, P. J.: User Guide to the Discrete Dipole Approximation Code DDSCAT 7.1, 2010.

Dubovik, O., Herman, M., Holdak, A., Lapyonok, T., Tanré, D., Deuzé, J. L., Ducos, F., Sinyuk, A., and Lopatin, A.: Statistically optimized inversion algorithm for enhanced retrieval of aerosol 
properties from spectral multi-angle polarimetric satellite observations, Atmos. Meas. Tech., 4, 975-1018, doi:10.5194/amt-4975-2011, 2011.

Dubovik, O., Dubovik, O., Sinyuk, A., Lapyonok, T., Holben, B. N., Mishchenko, M., Yang, P., Eck, T. F., Volten, H., Muñoz, O., Veihelmann, B., van der Zande, W. J., Leon, J.-F., Sorokin, M., and Slutsker, I.: Application of spheroid models to account for aerosol particle non-sphericity in remote sensing of desert dust, J. Geophys. Res., 111, D11208, doi:10.1029/2005JD006619, 2006.

Flanner, M. G., Liu, X., Zhou, C., Penner, J. E., and Jiao, C.: Enhanced solar energy absorption by internally-mixed black carbon in snow grains, Atmos. Chem. Phys., 12, 4699-4721, doi:10.5194/acp-12-4699-2012, 2012.

Fuller, K. A., Malm, W. C., and Kreidenweis, S. M.: Effects of mixing on extinction by carbonaceous particles, J. Geophys. Res., 104, 15941-15954, 1999.

Hasekamp, O., Litvinov, P., and Butz, A.: Aerosol properties over the ocean from PARASOL multiangle photopolarimetric measurements, J. Geophys. Res., 116, 2156-2202, doi:10.1029/2010JD015469, 2011.

Heinson, W. R., Sorensen, C. M., and Chakrabarti, A.: Does shape anisotropy control the fractal dimension in diffusionlimited cluster-cluster aggregation?, Aerosol Sci. Tech., i-iv, 44, doi:10.1080/02786826.2010.516032, 2010.

IPCC (Ed.): Climate Change 2007: The Physical Science Basis, Summary for Policy Makers, 2007.

Jacobson, M.: A physically-based treatment of elemental carbon optics: Implications for global direct forcing of aerosol, Geophys. Res. Lett., 27, 217-220, 2000.

Jacobson, M.: Strong radiative heating due to mixing state of black carbon in atmospheric aerosol, Letters to Nature, 409, 695-697, doi:10.1038/35055518, 2001.

Kahnert, M.: On the discrepancy between modeled and measured mass absorption cross sections of light absorbing carbon aerosols, Aerosol Sci. Tech., 44, 453-460, doi:10.1080/02786821003733834, 2010a.

Kahnert, M.: Numerically exact computation of the optical properties of light absorbing carbon aggregates for wavelength of $200 \mathrm{~nm}-12.2 \mu \mathrm{m}$, Atmos. Chem. Phys., 10, 8319-8329, doi:10.5194/acp-10-8319-2010, 2010 b.

Kahnert, M. and Devasthale, A.: Black carbon fractal morphology and short-wave radiative impact: a modelling study, Atmos. Chem. Phys., 11, 11745-11759, doi:10.5194/acp-11-117452011, 2011.

Kahnert, M., Nousiainen, T., Lindqvist, H., and Ebert, M.: Optical properties of light absorbing carbon aggregates mixed with sulfate: assessment of different model geometries for climate forcing calculations, Opt. Express, 20, 10042-10058, doi:10.1364/OE.20.010042, 2012.

Kanakidou, M., Seinfeld, J. H., Pandis, S. N., Barnes, I., Dentener, F. J., Facchini, M. C., Van Dingenen, R., Ervens, B., Nenes, A., Nielsen, C. J., Swietlicki, E., Putaud, J. P., Balkanski, Y., Fuzzi, S., Horth, J., Moortgat, G. K., Winterhalter, R., Myhre, C. E. L., Tsigaridis, K., Vignati, E., Stephanou, E. G., and Wilson, J.: Organic aerosol and global climate modelling: a review, Atmos. Chem. Phys., 5, 1053-1123, doi:10.5194/acp-5-1053-2005, 2005.

Kaufman, Y., Tanre, D., and Boucher, O.: A satellite view of aerosols in the climate system, Nature, 419, 215-223, 2002.
Kirchstetter, T. and Novakov, T.: Controlled generation of black carbon particles from a diffusion flame and applications in evaluating black carbon measurement methods, Atmos. Environ., 41, 1874-1888, 2007.

Laskin, A., Moffet, R., Gilles, M. K., Fast, J. D., Zaveri, R. A., Wang, B., Nigge, P., and Shutthanandan, J.: Tropospheric chemistry of internally mixed sea salt and organic particles: Surprising reactivity of nacl with weak organic acids, J. Geophys. Res., 117, 2156-2202, doi:10.1029/2012JD017743, 2012.

Li, J., Anderson, J. R., and Buseck, P. R.: Tem study of aerosol particles from clean and polluted marine boundary layers over the north atlantic, J. Geophys. Res., 108, 2156-2202, doi:10.1029/2002JD002106, 2003.

Liou, K., Takano, Y., and Yang, P.: Light absorption and scattering by aggregates: Application to black carbon and snow grains, J. Quant. Spectrosc. Ra., 112, 1581-1594, 2011.

Liu, C., Panetta, R. L., and Yang, P.: The influence of water coating on the optical scattering properties of fractal soot aggregates, Aerosol Sci. Tech., 46, 31-43, doi:10.1080/02786826.2011.605401, 2012.

Liu, L., Michael, I., Mishchenko, W., and Arnott, P.: A study of radiative properties of fractal soot aggregates using the superposition T-matrix method, J. Quant. Spectrosc. Ra., 109, 2656-663, 2008.

Martins, J., Artaxo, P., Liousse, C., Reid, J. S., Hobbs, P. V., and Kaufman, Y. J.: Effects of black carbon content, particle size, and mixing on light absorption by aerosols from biomass burning in brazil, J. Geophys. Res., 103, 32041-32050, doi:10.1029/98JD02593, 1998.

Maxwell Garnett, J.: Colours in metal glasses and in metallic films, Phil. Trans. R. Soc. Lond., 203, 359-371, 385-420, doi:10.1098/rsta.1904.0024, 1904.

Mikhailov, E. F., Vlasenko, S. S., Podgorny, I. A., Ramanathan, V., and Corrigan, C. E.: Optical proprieties of soot water drop agglomerates: an experimental study, J. Geophys. Res., 111, 21562202, doi:10.1029/2005JD006389, 2006.

Mishchenko, M. I. and Travis, L.: Satellite retrieval of aerosol properties over the ocean using polarization as well as intensity of reflected sunlight, J. Geophys. Res., 102, 16989-17013, 1997a.

Mishchenko, M. I. and Travis, L. D.: Satellite retrieval of aerosol properties over the ocean using measurements of reflected sunlight: Effect of instrumental errors and aerosol absorption, J. Geophys. Res., 102, 13543-13553, 1997b.

Mischenko, M., Wiscombe, W., Hovenier, J., and Travis, L.: Overview of scattering by nonsperical particles, in: Light scattering by nonsperical particles: theory, measurements and applications, edited by: Mishchenko, M. I., Hovenier, J. W., and Travis, L. D., Academic Press, 29-60, 2000.

Mishchenko, M., Travis, L. D., and Lacis, A. A.: Scattering, absorption, and emission of light by small particles, Cambridge University Press, Cambridge, 2002.

Mishchenko, M. I., Travis, L. D., and Mackowski, D. W.: T-matrix computations of light scattering by nonspherical particles: A review, J. Quant. Spectrosc. Ra., 55, 535-575, doi:10.1016/00224073(96)00002-7, 1996.

Moffet, R. and Prather, K.: In-situ measurements of the mixing state and optical properties of soot with implications for radiative forcing estimates, P. Natl. Acad. Sci., 106, 11872-11877, 2009. 
Moosmuller, H., Chakrabarty, R., and Arnott, W.: Aerosol light absorption and its measurement: A review, J. Quant. Spectrosc. Ra., 110, 844-878, doi:10.1016/j.jqsrt.2009.02.035, 2009.

Pace, G., di Sarra, A., Meloni, D., Piacentino, S., and Chamard, P.: Aerosol optical properties at Lampedusa (Central Mediterranean). 1. Influence of transport and identification of different aerosol types, Atmos. Chem. Phys., 6, 697-713, doi:10.5194/acp-6-697-2006, 2006.

Purcell, E. and Pennypacker, C.: Scattering and Absorption of Light by Nonspherical Dielectric Grains, Astrophys. J., 186, 705-714, doi:10.1086/152538, 1973.

Ramanathan, V. and Carmichael, G. R.: Global and regional climate changes due to BC, Nature, 1, 221-227, 2008.

Russell, P. B., Bergstrom, R. W., Shinozuka, Y., Clarke, A. D., DeCarlo, P. F., Jimenez, J. L., Livingston, J. M., Redemann, J., Dubovik, O., and Strawa, A.: Absorption Angstrom Exponent in AERONET and related data as an indicator of aerosol composition, Atmos. Chem. Phys., 10, 1155-1169, doi:10.5194/acp-101155-2010, 2010.

Shen, Y., Draine, B. T., and Eric, T. J.: Modeling Porous Dust Grains with Ballistic Aggregates. I. Geometry and Optical Properties, Astrophys. J., 689, 260 pp., 2008.

Shen, Y., Draine, B. T., and Johnson, E. T.: Modeling porous dust grains with ballistic aggregates. ii. light scattering properties, Astrophys. J., 696, 2126-2137, doi:10.1088/0004637X/696/2/2126, 2009.

Shiraiwa, M., Kondo, Y., Moteki, N., Takegawa, N., Miyazaki, Y., and Blake, D. R.: Evolution of Mixing State of Black Carbon in Polluted Air from Tokyo, Geophys. Res. Lett., 34, L16803, doi:10.1029/2007GL029819, 2007.

Shiraiwa, M., Kondo, Y., Iwamoto, T., and Kita, K.: Amplification of light absorption of black carbon by organic coating, Aerosol Sci. Tech., 44, 46-54, doi:10.1080/02786820903357686, 2010.

Smirnov, A., Holben, B. N., Giles, D. M., Slutsker, I., O’Neill, N. T., Eck, T. F., Macke, A., Croot, P., Courcoux, Y., Sakerin, S. M., Smyth, T. J., Zielinski, T., Zibordi, G., Goes, J. I., Harvey, M. J., Quinn, P. K., Nelson, N. B., Radionov, V. F., Duarte, C. M., Losno, R., Sciare, J., Voss, K. J., Kinne, S., Nalli, N. R., Joseph, E., Krishna Moorthy, K., Covert, D. S., Gulev, S. K., Milinevsky, G., Larouche, P., Belanger, S., Horne, E., Chin, M., Remer, L. A., Kahn, R. A., Reid, J. S., Schulz, M., Heald, C. L., Zhang, J., Lapina, K., Kleidman, R. G., Griesfeller, J., Gaitley, B. J., Tan, Q., and Diehl, T. L.: Maritime aerosol network as a component of AERONET - first results and comparison with global aerosol models and satellite retrievals, Atmos. Meas. Tech., 4, 583-597, doi:10.5194/amt-4-583-2011, 2011.
Tian, K., Thomson, K., Liu, F., Snelling, D., Smallwood, G., and Wang, D.: Determination of the morphology of soot aggregates using the relative optical density method for the analysis of tem images, Combust. Flame, 144, 782-791, doi:10.1016/j.combustflame.2005.06.017, 2006.

Tyynelae, J., Zubko, E., Videen, G., and Muinonen, K.: Interrelating angular scattering characteristics to internal electric fields for wavelength-scale spherical particles, J. Quant. Spectrosc. Ra., 106, 520-534, doi:10.1016/j.jqsrt.2007.01.032, 2007.

Worringen, A., Ebert, M., Trautmann, T., Weinbruch, S., and Helas, G.: Optical properties of internally mixed ammonium sulfate and soot particles-a study of individual aerosol particles and ambient aerosol populations, Appl. Optics, 47, 3835-3845, doi:10.1364/AO.47.003835, 2008.

Wu, Y., Gu, X., Cheng, T., Xie, D., Yu, T., Chen, H., and Guo, J.: The single scattering properties of the aerosol particles as aggregated spheres, J. Quant. Spectrosc. Ra., 113, 1454-1466, doi:10.1016/j.jqsrt.2012.03.015, 2012.

Xue, H., Khalizov, A. F., Wang, L., Zheng, J., and Zhang, R.: Effects of dicarboxylic acid coating on the optical properties of soot, Chem. Chem. Phys., 11, 7869-7875, doi:10.1039/B904129J, 2009.

Zhang, R., Khalizov, A. F., Pagels, J., Zhang, D., Xue, H., and McMurry, P. H.: Variability in morphology, hygroscopicity, and optical properties of soot aerosols during atmospheric processing, P. Natl. Acad. Sci., 105, 10291-10296, doi:10.1073/pnas.0804860105, 2008.

Zhao, Y. and Ma, L.: Applicable range of the rayleigh-debye-gans theory for calculating the scattering matrix of soot aggregates, Appl. Optics, 48, 591-597, doi:10.1364/AO.48.000591, 2009. 